Article

\title{
Optimization Design of RV Reducer Crankshaft Bearing
}

\author{
Jian Huang $®$, Chaoyang $\mathrm{Li}^{*}$ and Bingkui Chen
}

State Key Laboratory of Mechanical Transmission, Chongqing University, Chongqing 400044, China; huangjian@cqu.edu.cn (J.H.); bkchen@cqu.edu.cn (B.C.)

* Correspondence: li_zhaoyang77@cqu.edu.cn; Tel.: +86-023-6510-6247

Received: 28 July 2020; Accepted: 15 September 2020; Published: 18 September 2020

check for updates

\begin{abstract}
The crankshaft bearing is the key component of a rotate vector (RV) reducer. However, owing to the harsh working load and restricted available space, the bearing often suffers from fatigue failure. Therefore, this study proposes a novel optimization method for RV reducer crankshaft bearings. A nonlinear constraint optimization model for the design of the bearing considering the crowned roller profile is formulated and is solved by using a crow search algorithm. The goal of the optimization is to maximize the fatigue life of the bearing. The design variables corresponding to the bearing geometry and crowned roller profile are considered. The load working conditions of the bearing and structure of the RV reducer are analyzed. Various constraints, including geometry, lubrication, strength of the bearing, and structure of the RV reducer, are established. Through the optimization design, the optimum crowned roller profile suitable for the working load of the bearing is obtained, and the stress concentration between the roller and raceway is eliminated. Taking the crankshaft bearing of RV-20E and RV-110E type reducers as examples, the bearings were optimized by the proposed method. After optimization, the bearing life of the RV-20E type reducer is increased by $196 \%$, and the bearing life of the RV-110E type reducer is increased by $168 \%$.
\end{abstract}

Keywords: RV reducer; crankshaft bearing; fatigue life; bearing design; bearing optimization

\section{Introduction}

The rotate vector (RV) reducer is widely used in industrial robots because of its compact structure, small size, high torsional rigidity, large transmission ratio, and great load capacity $[1,2]$. Service life is one of the most important performance parameters of a reducer. However, the harsh working environment makes the reducer prone to fail easily [3]. Thus, it is important to investigate the fatigue life of the RV reducer.

For an RV reducer, the service life mainly depends on the rated life of crankshaft bearings $[4,5]$. Both the RV reducer sample manuals of Nabtesco and standard GB/T37718 take the rated life of the crankshaft bearing as the service life of the reducer. However, the load working condition of the crankshaft bearings are very complex, and the radial size is very small. Therefore, the crankshaft bearings often suffer fatigue failure, which limits the service life of the RV reducer [4]. Therefore, crankshaft bearings use non-standard cylindrical roller bearings $[4,5]$. For nonstandard bearing, it takes a lot of time to design the bearing with the traditional trial and error method [6]. In addition, the design of the bearing must satisfy various constraints, e.g., geometrical, kinematical, and mechanical constraints. Therefore, it is necessary to use optimization techniques for crankshaft bearings to improve the service life of the reducer.

In recent years, there has been abundant research focused on RV reducers. Li [7] proposed an analytical model for the cycloidal gear considering tooth profile modification. Han [8] analyzed the sensitivity of transmission accuracy of RV reducers. Xu [9] researched the measurement of the 
backlash of RV reducers. Hsieh [10] established an analytical model of system dynamics in cycloidal pin gear reducers with small tooth differences. Jin [11] analyzed the transmission error of the RV reducer by using virtual machine technology. Wang [12] proposed a new contact model of cycloidal meshing pair and analyzed the transmission accuracy of RV reducer. The influence of tooth profile modification was analyzed. Li [13] analyzed the meshing characteristics of RV reducers considering the manufacturing error. Chen [14] analyzed the vibration characteristics of the RV reducer. $\mathrm{Xu}$ [4] established a dynamic model of the RV reducers. The transmission mechanisms of cycloidal gear were analyzed. Wei [15] analyzed the lubrication characteristics of RV reducers. Zhang [5] analyzed the mixed lubrication of crankshaft bearings of an RV reducer. Wang [16] used genetic algorithm to optimize the design of cycloid reducer. Chu [17] proposed a selective assembly method for RV reducers using genetic algorithms. Wang [18] proposed a multi-objective optimization method for cycloidal speed reducer. The objective functions are the reducer volume, loads on the crankshaft bearings, and stress of cycloidal gear.

The above review shows that most of the published works focus on the meshing characteristics of the cycloidal pair, tooth profile modification, and performance characteristics of the RV reducer. However, few scholars have focused on optimizing the fatigue life of the reducers. Although studies [16,18] have optimized the fatigue life of cycloidal reducers by using a multi-objective optimization method, the geometric parameters and roller profile of the bearing have not been comprehensively considered during the optimization design.

Therefore, an optimization method for RV reducer crankshaft bearings considering the bearing geometry and crowned roller profile is presented. First, the performance of the bearing considering the load working condition and roller profile is analyzed. Second, a mathematical model for the optimization design is developed. Third, two types of crankshaft bearings are optimized by the proposed optimization method. A comparison of the parameters of the bearing before and after optimization is presented. Finally, a research summary of the study is provided.

\section{Performance of Crankshaft Bearings of Rotate Vector (RV) Reducers}

Crankshaft bearings are the key components restricting the service life of RV reducers. The performance of the bearing is analyzed in this section. First, the structure of the RV reducers is analyzed. Second, the loads on the crankshaft bearing in the reducer are calculated. Finally, the fatigue life of the crankshaft bearing considering the clearance and crowned roller profile is evaluated.

\subsection{Structure of RV Reducer}

The RV reducer is a two-stage planetary transmission mechanism. The first stage is involute gear transmission. The second stage is cycloid gear transmission. Figure 1 is the structure of the RV reducer. In a cycloidal-pinwheel transmission, the crankshaft and cycloidal gear are connected by the crankshaft bearing. The off-center section of the crankshafts causes the cycloidal gear to rotate in eccentricity. The cycloidal gear meshes with the pin gear. Therefore, the cycloid gear also rotates around its own axis. The crankshaft transmits the spinning motion of the cycloidal gear to the output mechanism of the reducer.

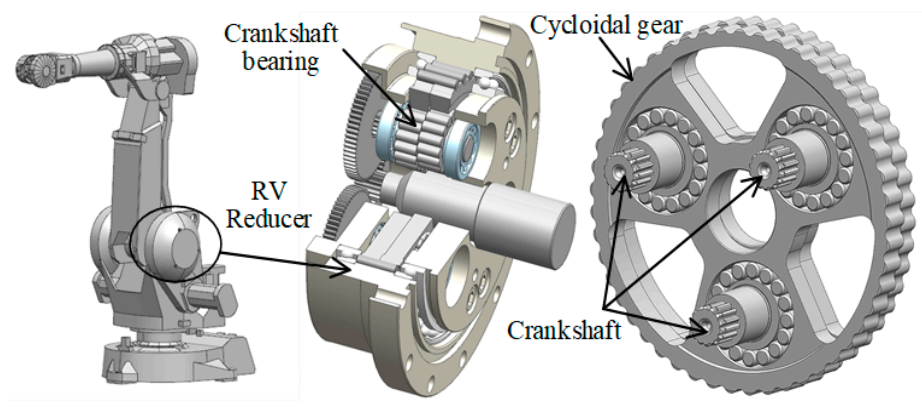

Figure 1. Structure of rotate vector (RV) reducer. 
Crankshaft bearing is mainly composed of rollers, inner raceways, and outer raceways. Because of the restriction of available space, a cylindrical roller bearing without inner and outer rings is used for the crankshaft bearing. As shown in Figure 2, the outer raceway is integrated into the cycloidal gear.

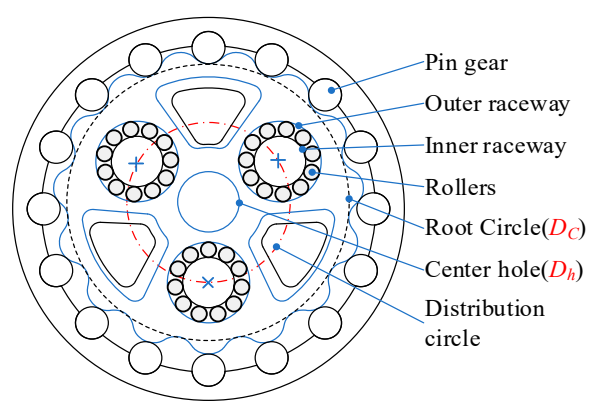

(a)

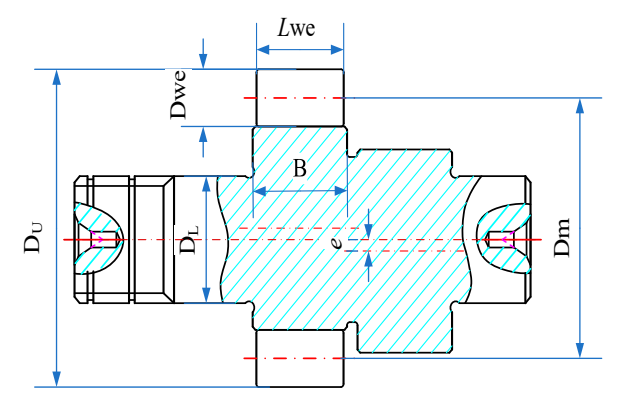

(b)

Figure 2. Schematic diagram of crankshaft bearing structure: (a) Cross-section of the RV reducer with crankshaft bearing; (b) Structure of the crankshaft bearing.

The size of the outer raceway is limited by the root circle and the center hole of the cycloidal gear. The inner raceway is integrated into the off-center section of the crankshaft. The radius of the crankshaft bearing distribution circle determines the installation position of the crankshaft bearing in the cycloidal gear. The width of the off-center section is the same as the width of the cycloidal gear, which limits the length of the roller.

Although the components of the crankshaft bearings appear simple, the macro geometry has significant effects on mechanical behavior of bearing. The macro-geometric parameters mainly include the roller length $L_{w e}$, roller diameter $D_{w e}$, bearing pitch diameter $D_{m}$, and radial clearance $P_{d}$. As shown in Figure 2, the boundary dimensions include the outer diameter $\left(D_{U}\right)$, minimum diameter of crankshaft $\left(D_{L}\right)$, bearing width $(\mathrm{B})$, diameter of the center hole $\left(D_{h}\right)$, and the root circle of the cycloidal gear $\left(D_{c}\right)$.

\subsection{Force Analysis of Crankshaft Bearings}

A Cartesian coordinate system, xoy, is employed to analyze the load of the crankshaft bearings. The origin is located at the center of the distribution circle of the pin gears. The direction of the $y$ axis coincides with the eccentric direction of the crankshaft. The cycloidal gear bears the forces from the pin gear and crankshaft bearings. The component forces of pin gears on cycloid gear along the $x$-axis and $y$-axis are $\sum P_{i x}$ and $\sum P_{i y}$, respectively. The forces acting on the cycloidal gear by the crankshaft bearing are decomposed into, $F_{j 1}, F_{j 2}$, and $F_{j 3}$. The torque caused by the force $F_{j 1}$ is balanced with the torque caused by the force $\sum p_{i x}$. The force $F_{j 2}$ is balanced with force $\sum P_{i x}$ and $F_{j 3}$ is balanced with $\sum P_{i y}$. This can be obtained from the force balance on the cycloidal gear:

$$
\left\{\begin{array}{c}
F_{\mathrm{j} 1}=\frac{1}{n} \sum P_{i x} \frac{e z_{g}}{r_{o}} \\
F_{j 2}=\frac{1}{n} \sum P_{i x} \\
F_{j 3}=\frac{K_{y}}{n} \sum P_{i y}
\end{array}\right.
$$

where $\sum P_{i y}=K_{y} \sum P_{i x}$ and $K_{y}=\frac{2}{\pi}\left[\frac{1}{k}+\frac{k^{2}-1}{2 k^{2}} \ln \frac{1+k}{1-k}\right], k$ is the short width coefficient and $k=e Z_{\mathrm{b}} / R_{z}$, $z_{\mathrm{b}}$ is the number of pin teeth, $e$ is the eccentric distance of the crankshaft, $z_{\mathrm{g}}$ is the number of cycloidal gear teeth, and $R_{z}$ and is the radius of distribution circle of the pin gear.

It is assumed that the output torque of the reducer is $T_{v}$. For the torque equilibrium of the cycloidal gear,

$$
\sum p_{i x}=\frac{T_{v}}{2 e z_{g}}
$$


In Figure $3 \mathrm{~b}, o_{1}$ is the center of the cycloidal gear. $o_{c}$ is the center of the crankshaft bearing. The coordinate system $x_{1} o_{c} y_{1}$ is rigidly connected with the crankshaft bearing. The angle between the $y_{1}$ and $y$ axes is $\theta$. It is assumed that the force between the crankshaft bearing and the cycloidal gear is $F$. $F$ can be decomposed into the normal force $F_{r}$ and tangential force $F_{t} . F_{r}$ is in the direction of the axis $x_{1} . F_{t}$ is in the direction of the axis $y_{1}$. The forces acting on the cycloidal gear by the crankshaft bearing are decomposed into $F_{j 1}, F_{j 2}$, and $F_{j 3}$. According to the balance between the acting and reaction forces,

$$
\left\{\begin{array}{c}
F_{t}=F_{j 1}+F_{j 2} \cos \theta-F_{j 3} \sin \theta \\
F_{r}=F_{j 2} \sin \theta+F_{j 3} \cos \theta
\end{array}\right.
$$

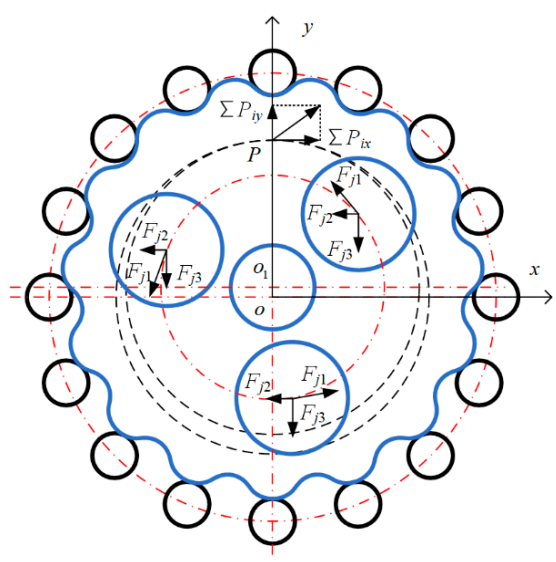

(a)

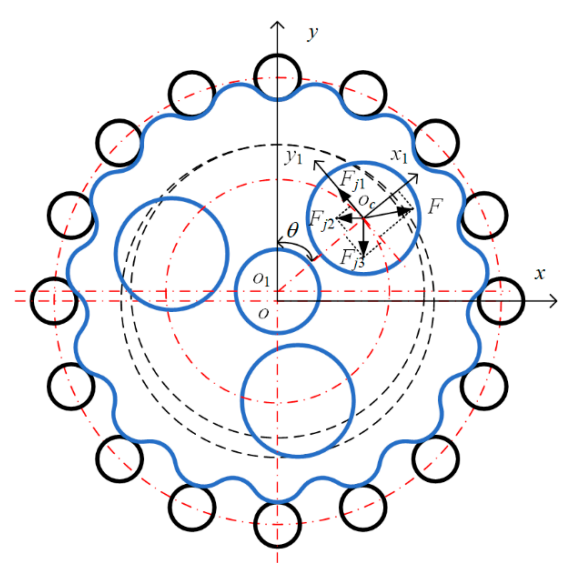

(b)

Figure 3. Force diagram of RV reducer: (a) Forces on cycloidal gear; (b) Forces on a crankshaft bearing.

Therefore, the resultant force acting on the crank bearing is

$$
F=\sqrt{F_{t}^{2}+F_{r}^{2}}=\frac{T v}{2 e z_{g} r_{o}} \sqrt{\left(e z_{g}\right)^{2}+r_{o}^{2}+k_{y}{ }^{2} r_{o}^{2}+2 e z_{g} r_{o} \cos \theta-2 k_{y} e z_{g} r_{o} \sin \theta}
$$

From the above equation, the load of the crankshaft bearing changes periodically as the crank shaft rotates. The load change period was $2 \pi$. According to Harris et al. [19], the equivalent load of the crankshaft bearing can be calculated by

$$
F_{m}=\left(\frac{1}{2 \pi} \int_{0}^{2 \pi} F^{4} d_{\theta}\right)^{1 / 4}
$$

The equivalent load of the bearing obtained through integration is

$$
F_{m}=\frac{T_{v}}{2}\left(\frac{\left(e z_{g}\right)^{4}+4\left(1+k_{y}^{2}\right)\left(e z_{g}\right)^{2} r_{o}^{2}+\left(1+k_{y}^{2}\right)^{2} r_{o}^{4}}{n^{4}\left(e z_{g}\right)^{4} r_{o}^{4}}\right)^{1 / 4}
$$

\subsection{Fatigue Life of Crankshaft Bearings}

In cases where the rolling elements are only lightly profiled or subjected to excessive loads, edge stresses can arise, which need to be considered in the rating life calculation. Therefore, both the roller profile and macro-geometric parameters are considered in this study. First, the load distribution is calculated using the quasi-static method. Then, the distribution of the contact stress over the length of the rollers is calculated using the non-Hertzian contact method. Finally, the fatigue life of the bearing is evaluated by considering the contact stress of the rollers. 


\subsubsection{Load Distribution of Crankshaft Bearings}

As shown in Figure 4, the radial load $F_{m}$ from the cycloidal gear acts on the crankshaft bearings. It is assumed that the relative radial displacement between the crankshaft and the cycloidal gear is $\delta_{r}$. It can be seen from the deformation coordination relationship that the radial deflection at any roller angular position $\psi_{j}$ is

$$
\delta_{r j}=\delta_{r} \cos \psi_{j}-\frac{\mathrm{P}_{d}}{2}
$$

where $\psi_{j}$ is the angular position of the $j$ th roller and $P_{d}$ is the radial clearance.

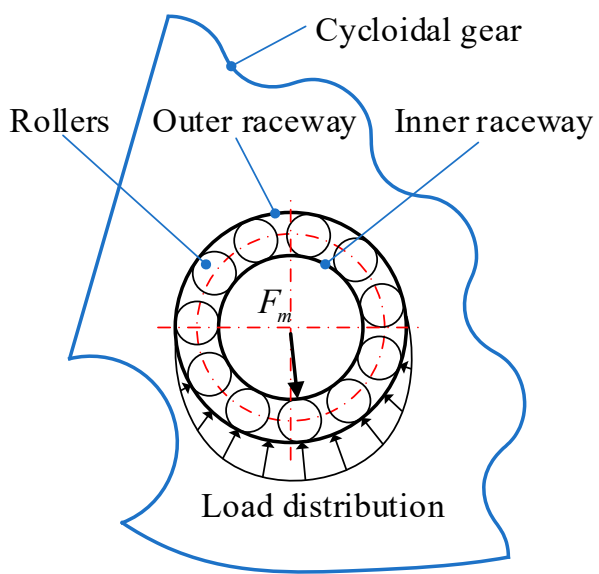

(a)

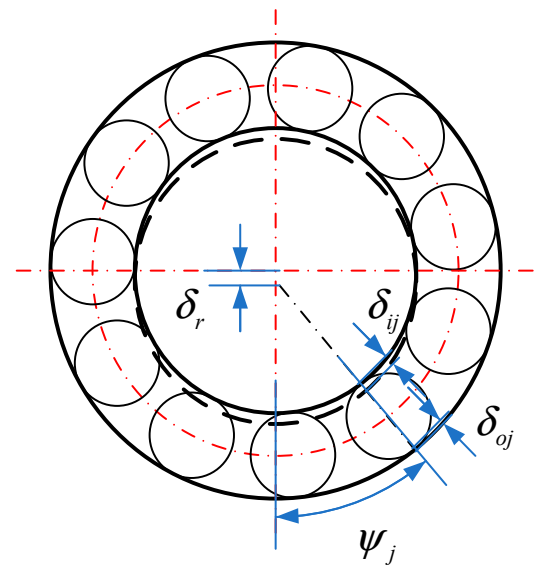

(b)

Figure 4. Load distribution of bearing: (a) Load distribution of crankshaft bearing; (b) Bearing ring displacement.

The total normal contact deformation between two raceways separated by a rolling element under a load is the sum of the deformations between the rolling element and each raceway. Hence,

$$
\delta_{r j}=\delta_{i j}+\delta_{o j}
$$

where $\delta_{i j}$ is the normal contact deformation between inner raceway and the $j$ th roller, and $\delta_{o j}$ is the contact deformation between the outer raceway and the $j$ th roller.

The roller at the angular position $\psi_{j}$ is subjected to forces from the raceways $Q_{o j} / Q_{i j}$. The normal roller loads are related to normal contact deformations as follows [19]:

$$
\left\{\begin{array}{l}
Q_{o j}=K_{c} \delta_{o j}^{10 / 9} \\
Q_{i j}=K_{c} \delta_{i j}^{10 / 9}
\end{array}\right.
$$

According to Harris [19], for the steel roller-steel raceway contact,

$$
K_{c}=8.06 \times 10^{4} L_{w e}^{8 / 9}
$$

The roller is subjected to the forces from the raceways and the centrifugal force $F_{c}$. Thus, considering the force equilibrium,

$$
Q_{o j}-Q_{i j}-F_{c}=0
$$

The centrifugal force for a steel roller orbiting at speed $n_{m}$ about a bearing axis is given by

$$
F_{\mathrm{c}}=3.39 \times 10^{-11} D_{w e}^{2} L_{w e} d_{m} n_{m}^{2}
$$


Substituting Equations (7)-(10) into Equation (11), Equation (11) can be rewritten as follows:

$$
K_{c}\left(\delta_{r} \cos \psi_{j}-\frac{\mathrm{P}_{d}}{2}-\delta_{i j}\right)^{10 / 9}-K_{c} \delta_{i j}^{10 / 9}-F_{c}=0
$$

For static equilibrium, the radial load must be equal to the sum of the vertical components of the roller loads:

$$
F_{m}-K_{c} \sum_{j}^{Z} \delta_{i j}^{10 / 9} \cos \psi_{j}=0
$$

Equations (13) and (14) are a system of simultaneous nonlinear equations. $\delta r$ and $\delta_{i j}$ are unknown and need to be solved. The equations are solved by Newton-Raphson method. Thereafter, roller loads are obtained using Equation (9).

\subsubsection{Roller-Raceway Contact Stress}

Hertzian contact is often used to solve the contact stress between two cylinders. However, it cannot reveal the stress concentration and the effect of the roller profile. Non-Hertzian contact method can reveal the effect of the roller profile. The distribution of the contact stress over the length of the rollers can be obtained by using non-Hertzian theory. Therefore, it is adopted in this study.

The contact forces between the raceway and roller were calculated using the quasi-static model. When the roller is subjected to a normal load $Q$, it is assumed that the contact area between the raceway and the roller is $A$. The contact pressure at coordinate $(x, y)$ is $P(x, y)$. The integral of pressure $P(x, y)$ is equal to the contact force $Q$.

$$
\int_{A} P(x, y) d x d y=Q
$$

Contact stress occurs when two surfaces come into contact with each other. Assuming that the contact deformation between the two surfaces at coordinate $(x, y)$ is $\delta(x, y)$, then

$$
\begin{cases}P(x, y)=0, & \text { if } \delta(x, y)<0 \\ P(x, y)>0, & \text { if } \delta(x, y) \geq 0\end{cases}
$$

According to the half-space theory, when two bodies come into contact, the elastic deformation $\delta(x, y)$ can be expressed by the following equation:

$$
\delta(x, y)=\frac{2}{E^{\prime}} \int_{A} \frac{P\left(x^{\prime}, y^{\prime}\right) d x^{\prime} d y^{\prime}}{\sqrt{\left(x-x^{\prime}\right)^{2}+\left(y-y^{\prime}\right)^{2}}}
$$

where $E^{\prime}$ is the equivalent Young's modulus.

$$
E^{\prime}=\frac{E}{1-v^{2}}
$$

where $v$ is the Poisson's ratio and $E$ is the elastic modulus.

When the roller is subjected to the normal load $Q$, the contact surfaces are moved toward each other by a displacement $\delta$. For a roller with a crowned profile, $z(x, y)$ is the gap between the roller and raceway at the coordinate $(x, y)$ generated by the crown drop. $f(x, y)$ is the initial distance generated by the geometry of the roller and raceway. Therefore, Equation (17) can be written as follows:

$$
\frac{2}{E^{\prime}} \int_{A} \frac{P\left(x^{\prime}, y^{\prime}\right) d x^{\prime} d y^{\prime}}{\sqrt{\left(x-x^{\prime}\right)^{2}+\left(y-y^{\prime}\right)^{2}}}=\delta-f(x, y)-z(x, y)
$$


In these equations, the relative displacement $\delta$, pressure distribution $P(x, y)$, and contact area $A$ are unknown. To simplify this problem, the contact area is subdivided into multiple discrete cells. It is assumed that the contact pressure distribution on each cell is constant. Therefore, the integral is replaced by a summation, represented as

$$
\sum_{j=1}^{r} P_{j} f_{i j}=D_{i}, i=1,2 \cdots r
$$

where $f_{i j}$ is the influence coefficient representing the deflection of cell $i$ because of a uniform pressure over the cell $j$, which can be obtained according to reference [20]. $D_{i}$ is the contact deformation of cell $i$.

Finally, the equilibrium condition of the applied contact force and the integral of the pressure over the contact yields:

$$
\frac{Q}{A}-\sum_{j=1}^{r} P_{j}=0
$$

Equations (20) and (21) are solved simultaneously for the contact area and contact stress.

\subsubsection{Fatigue Life}

The basic dynamic load rating of the raceways $Q_{c i} / Q_{c o}$ are obtained by

$$
\left\{\begin{array}{l}
Q_{c i}=\frac{1}{\lambda \eta} \frac{C_{r}}{0.378 Z}\left\{1+\left[1.038\left(\frac{1-\gamma}{1+\gamma}\right)^{143 / 108}\right]^{9 / 2}\right\}^{2 / 9} \\
Q_{c o}=\frac{1}{\lambda \eta} \frac{C_{r}}{0.364 Z}\left\{1+\left[1.038\left(\frac{1-\gamma}{1+\gamma}\right)^{143 / 108}\right]^{-9 / 2}\right\}^{2 / 9}
\end{array}\right.
$$

According to ISO/TR 1281-1, the value of $\lambda \eta$ is $0.83 . \gamma$ is the parameter related to the structure of the bearing, $\gamma=D_{w e} / d_{m}$. The basic dynamic load capacity $C_{r}$ of the bearings is

$$
C_{r}=b_{m} f_{c} L_{w e}{ }^{7 / 9} Z^{3 / 4} D_{w e}{ }^{29 / 27}
$$

where $b_{m}$ accommodates recent improvements in bearing quality and standard ISO/TR 1281-1 gives values of the factor $b_{m}=1.1 . f_{c}$ is a factor related to the the geometry and the material of the bearings,

$$
f_{c}=207 \lambda \eta \frac{\gamma^{2 / 9}(1-\gamma)^{29 / 27}}{(1+\gamma)^{1 / 4}}\left\{1+\left[1.04\left(\frac{1-\gamma}{1+\gamma}\right)^{143 / 108}\right]^{9 / 2}\right\}^{-2 / 9}
$$

The contact stress along the roller over the length of the roller is considered. To this end, the rollers were discretized into a number $\left(n_{s}\right)$ of slices. The basic load capacity of a slice of the inner and outer rings, $q_{c i} / q_{c o}$, is

$$
\left\{\begin{array}{l}
q_{c i}=Q_{c i}\left(\frac{1}{n_{s}}\right)^{7 / 9} \\
q_{c o}=Q_{c o}\left(\frac{1}{n_{s}}\right)^{7 / 9}
\end{array}\right.
$$

The dynamic equivalent load on the $k$ th slice is:

$$
\left\{\begin{array}{l}
q_{e k i}=\left\{\frac{1}{Z} \sum_{j=1}^{Z}\left[\left(\frac{p_{i k j}}{271}\right)^{2} D_{w e}(1-\gamma) \frac{L_{w e}}{n_{s}}\right]^{4.5}\right\}^{1 / 4.5} \\
q_{e k o}=\left\{\frac{1}{Z} \sum_{j=1}^{Z}\left[\left(\frac{p_{o k j}}{271}\right)^{2} D_{w e}(1+\gamma) \frac{L_{w e}}{n_{s}}\right]^{4}\right\}^{1 / 4}
\end{array}\right.
$$


where $P_{o k j}$ is the contact stress at the $k$ th slice of $j$ th roller of outer ring and $P_{i k j}$ is the contact stress at the $k$ th slice of $j$ th roller of inner ring. The pressures were obtained in the previous section.

Finally, the reference bearing fatigue life is obtained as

$$
L_{10 r}=\left\{\sum_{k=1}^{n_{s}}\left[\left(\frac{q_{c i}}{q_{e k i}}\right)^{-4.5}+\left(\frac{q_{c o}}{q_{e k o}}\right)^{-4.5}\right]\right\}^{-8 / 9}
$$

\section{Mathematical Model of Optimization}

Crankshaft bearings are the key components restricting the service life of RV reducers. Therefore, crankshaft bearings are optimized in this study. The objective functions, design variables, and constraints in the optimization design are as follows:

\subsection{Definition of Design Variables}

The mechanical behavior of the crankshaft bearing is significantly affected by the macro-geometric structure of the bearing. The crowned profile gives an axially uniform pressure distribution. These factors significantly affect the fatigue life of the bearing. Therefore, the macro geometry and roller profile are considered in the optimization design. The design parameters of the macro geometry mainly include the roller diameter $D_{w e}$, number of rollers $Z$, bearing pitch diameter $D_{m}$, and radial clearance $\mathrm{P}_{d}$. In addition, the radius of the crankshaft distribution circle $\left(r_{o}\right)$ determines the installation position of the crankshaft in the cycloidal gear and the force of the crankshaft bearing.

When the rolling elements are only lightly profiled or subjected to excessive loads, edge stresses can arise. Cylindrical rollers (or raceways) are usually crowned to solve this problem [19]. Fujiwara [21,22] proposed a modified logarithmic shape that allowed for a flat region on the roller, as shown in Figure 5. The crown drop in the axial direction at position $x$ is

$$
\begin{gathered}
z(x)=A_{c} \ln \frac{1}{1-\left(1-e^{\left(-\frac{z_{m}}{A_{c}}\right)}\right)\left(\frac{x-L_{w e} / 2}{K_{2} L_{w e} / 2}+1\right)^{2}} \\
A_{c}=\frac{2 K_{1} Q_{\max }}{\pi L_{w e} E^{\prime}}
\end{gathered}
$$

where $Q_{\max }$ is the maximum load acting on the rollers, $K_{1}$ is the load coefficient, $K_{2}$ is the coefficient of the crown length, and $Z_{m}$ is the crown drop at the edge of the roller end.

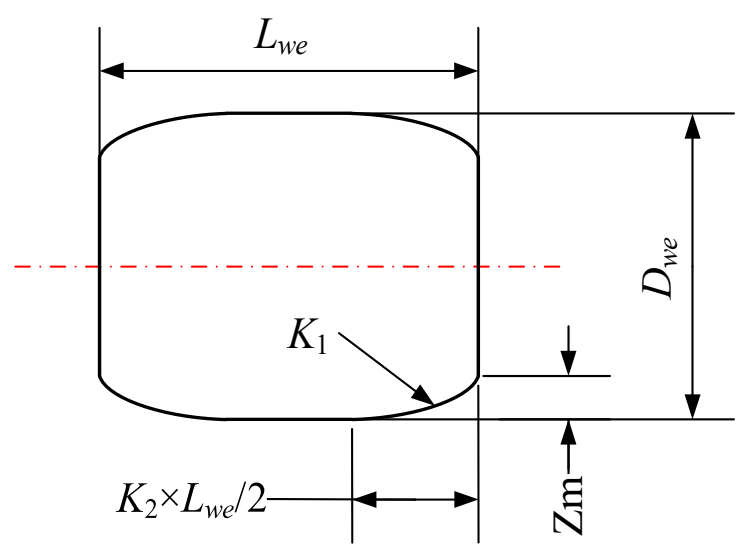

Figure 5. Logarithmic profile parameters of roller. 
Therefore, there are nine mutually independent design variables. $r_{0}, D_{w e}, D_{m}, L_{w e}, Z$, and $P_{d}$ define the internal geometric dimensions, and $K_{1}, K_{2}$, and $Z_{m}$ define the profile of the roller.

$$
X=\left[r_{0}, D_{w e}, D_{m}, L_{w e}, Z, P_{d}, K_{1}, K_{2}, Z_{m}\right]
$$

\subsection{Objective Function}

Crankshaft bearings are the key components limiting the service life of RV reducers. To improve the service life of the reducer, fatigue life of crankshaft bearings is taken as the objective function:

$$
\max [f(X)]=\max \left[L_{10 r}\right]
$$

where $X$ denotes the vector of design variable, and $f(X)$ is the objective function. The calculation method of $L_{10 r}$ is derived from Section 2.

\subsection{Constraint Conditions}

The design of crankshaft bearing must satisfy various constraints. In practice, the geometry of the crankshaft bearing is limited by the cycloidal gear. The crankshaft bearing should have sufficient load capacity. The crankshaft bearing should be well-lubricated to reduce wear and friction. The assembly conditions of RV reducer must be satisfied. In this section, the constraints conditions are derived from the geometry, lubrication, strength of crankshaft bearings, and structure of the RV reducer.

\subsubsection{Constraints on Bearing Pitch Diameter}

The outer raceway is located between the root circle and the center hole of the cycloidal gear. Therefore, the bearing pitch diameter should be smaller than the difference between the diameter of the center hole and the diameter of the root circle. The inner raceway of the bearing is integrated in the off-center section of the crankshaft. The eccentric distance of the crankshaft is $e$. Therefore,

$$
\left\{\begin{array}{c}
g_{1}(X)=\frac{D_{c}-D_{h}}{2}-\left(D_{m}+D_{w e}\right)>0 \\
g_{2}(X)=\left(D_{m}-D_{w e}+2 e\right)-D_{L}>0
\end{array}\right.
$$

\subsubsection{Constraints on Roller Diameter}

Geometric constraints of the cycloidal gear determine the upper bound of the roller diameter:

$$
g_{3}(X)=\left(\left(D_{c}-D_{h}\right) / 2-D_{L}\right) / 2-D_{w e}>0
$$

\subsubsection{Constraints on Roller Length}

For cylindrical roller bearings, the length of the roller should not be longer than 2.5 times the diameter of the rollers [23]. As shown in Figure 2, the roller length is not greater than the width of the crankshaft.

$$
\left\{\begin{array}{c}
g_{4}(X)=B-L_{w e}>0 \\
g_{5}(X)=2.5 D_{w e}-L_{w e}>0
\end{array}\right.
$$

\subsubsection{Constraints on Crowned Roller Profile}

$K_{1}, K_{2}$, and $Z_{m}$, are the parameters that control the profile of rollers. $K_{1}$ is the load coefficient, $K_{2}$ is the coefficient of the crown length, and $Z_{m}$ is the crown drop at the edge of the roller end. The ranges of the parameters for the logarithmic function are given by [22]

$$
\left\{\begin{array}{c}
g_{6}(X): 1<K_{1}<3 \\
g_{7}(X): 0<K_{2}<1 \\
g_{8}(X): 0<Z_{m}<0.02
\end{array}\right.
$$




\subsubsection{Constraints on Smooth Operation of the Bearing}

To guarantee smooth operation of the rollers without collision, an appropriate spacing should be provided between the rollers. The minimum angular spacing between the rollers is assumed to be greater than one in the crankshaft bearing [23].

$$
g_{9}(X)=2 \pi-2 Z \arctan \left(\frac{D_{w e}}{D_{m}}\right)-\frac{\pi}{180}>0
$$

\subsubsection{Constraints on Contact Strength}

The contact force is concentrated on a small contact area between the raceway and the roller. The contact pressure is very high, resulting in permanent deformation. Experience has shown that the permanent deformation is less than 0.0001 times the roller diameter to ensure safe operation of the bearing. Alternatively, the maximum contact pressure should be less than $4000 \mathrm{MPa}$ [24]. The contact stress is defined in Section 2.3.2. Thus,

$$
\left\{\begin{array}{l}
g_{10}(X)=4000-\max \left(p_{\mathrm{okj}}\right)>0 \\
g_{10}(X)=4000-\max \left(p_{i k j}\right)>0
\end{array}\right.
$$

\subsubsection{Lubricant Film Thickness Constraints}

Proper lubrication prevents severe friction between rollers and raceways. It can avoid metal-to-metal contact between raceway and roller. According to Dowson and Higginson [25], the minimum film thickness for inner and outer raceways is

$$
\left\{\begin{array}{l}
h_{\min }^{\text {in }}=\frac{2.65 \lambda \zeta^{0.54} \mu^{0.7} U_{\text {in }}^{0.7}\left(\frac{D_{w e e}}{2}(1-\gamma)\right)^{0.43}}{Q_{\max }^{0.13} E^{\prime 0.03}} \\
h_{\min }^{\text {out }}=\frac{2.65 \zeta^{0.54} \mu^{0.7} U_{\text {out }}^{0.7}\left(\frac{D_{w e}}{2}(1+\gamma)\right)^{0.43}}{Q_{\max }^{0.13} E^{0.03}}
\end{array}\right.
$$

where $\zeta$ is the pressure-viscosity coefficient, $\mu$ is viscosity of oil, $U_{\text {out }}$ is the sliding velocity between the outer raceway and the roller, $U_{i n}$ is the sliding velocity between the inner raceway and the roller, and $Q_{\max }$ is the maximum load on the rollers.

To assess the lubrication appropriateness, the film parameter $(\Lambda)$ is defined [19] as follows:

$$
\left\{\begin{array}{c}
\Lambda_{\text {in }}=\frac{h_{\min }^{\text {in }}}{\left(s_{m}^{2}+s_{R}^{2}\right)} \\
\Lambda_{\text {out }}=\frac{h_{\min }^{\text {out }}}{\left(s_{m}^{2}+s_{R}^{2}\right)}
\end{array}\right.
$$

where $h_{\text {min }}^{\text {out }}$ and $h_{\min }^{\text {in }}$ are the minimum lubricant film thickness for the outer and inner raceway, respectively. $s_{R}$ and $s_{m}$ is the root mean square roughness of the roller surface and the raceway surface, respectively. In this study, the value of $s_{m}$ and $s_{R}$ is $1.25 \mu \mathrm{m}$.

To ensure sufficient lubrication between the roller raceways, the film parameter value should be less than $3[6]$.

$$
\left\{\begin{array}{l}
g_{12}(X)=\frac{h_{\min }^{\text {in }}}{\left(s_{m}^{2}+s_{R}^{2}\right)}-3 \geq 0 \\
g_{13}(X)=\frac{h_{\text {min }}^{\text {out }}}{\left(s_{m}^{2}+s_{R}^{2}\right)}-3 \geq 0
\end{array}\right.
$$




\subsubsection{Constraints on Structure of RV Reducer}

For cylindrical roller bearings, the thickness of the bearing ring should not be less than $\varepsilon D_{w e}$, where $\varepsilon$ is between 0.3 and $0.4[23,26]$. The outer ring is integrated into the cycloidal gear. The thickness between the outer and center holes and the root circle is greater than $\varepsilon D_{w e}$.

$$
\left\{\begin{array}{l}
g_{14}(X)=r_{o}-\frac{D_{m}+D_{w e}}{2}-\frac{D_{h}}{2}+\varepsilon D_{w e}>0 \\
g_{15}(X)=\frac{D_{c}}{2}-\varepsilon D_{w e}-r_{o}-\frac{D_{m}+D_{w e}}{2}>0
\end{array}\right.
$$

To ensure the strength of the cycloidal gear, the value of $\varepsilon$ is 0.4 .

As shown in Figure 1, the planetary gears are fixed with crankshafts. The radius of the crankshaft bearing distribution circle is equal to the center distance of the sun gear and the planetary gear.

$$
r_{o}=\left(z_{1}+z_{2}\right) m
$$

where $z_{1}, z_{2}$ are the number of teeth of the sun gear and planetary gear, respectively, and $m$ is the gear module. The sun gear meshes with $n$ planet wheels.

According to the theory of planetary transmission, to ensure the assembly conditions of multiple planetary gears, the sum of the number of teeth of the sun and planetary gears should be an integer multiple of the number of planetary gears,

$$
\left(z_{1}+z_{2}\right) \bmod n=0
$$

Therefore, the radius of the crankshaft bearing distribution circle should be an integer multiple of the product of the number of planetary gears and the gear module:

$$
g_{16}(X)=r_{o} \bmod (n \times m)=0
$$

\subsection{Crow Search Algorithm}

In this study, the optimization of the crankshaft bearing is a typical constraint nonlinear optimization problem. Metaheuristic algorithms have shown promising performance for solving real-world optimization problems that are extremely nonlinear. The crow search algorithm (CSA) is a novel metaheuristic optimization method proposed by Askarzadeh [27]. The CSA has demonstrated its effectiveness and ability to solve many complex engineering optimization problems, such as environmental dispatch, renewable energy, and distribution networks [28]. Therefore, CSA is adopted to solve the optimization problem.

CSA is a population-based metaheuristic algorithm. It is based on the intelligent behavior of crows and searches for the optimal solution through iteration. CSA is initialized with a certain number of crows (flock size) with a random position. The position of each crow represents a solution to the optimization problem. A vector is used to define the position of the crow. The vector dimension represents the number of design variables. During the iteration, the position of each crow is updated. There are two parameters to control the generating of the position. They are flight length and awareness probability respectively. The best solution of each crow is memorized during the iteration. The optimization process stops when the maximum number of iterations is reached. The best position of the crows is select as the optimal solution to the optimization problem.

In Section 3.3, constraints on geometry, lubrication, contact strength of crankshaft bearings, and structure of the RV reducer are defined. To deal with the constraints, the penalty method is adopted in this study. The constrained problem is transformed into an unconstrained problem by the penalty function. 
The penalty function is defined as

$$
\Pi\left(X, \mu_{i}, v_{\mathrm{j}}\right)=f(X)-\sum_{i=1}^{M} \tau_{i} H_{i}\left[g_{i}(X)\right] g_{i}^{2}(X)-\sum_{j=1}^{N} v_{j} F_{j}[\xi(X)] \xi_{j}^{2}(X)
$$

where $\tau_{i} \gg 1$ and $v_{j} \geq 0$. These penalty function parameters should be sufficiently large for this application, but the values depend on the required quality of the solution. $M$ is the number of inequality constraints, and $N$ is the number of equality constraints.

$H_{i}\left[g_{i}(X)\right]$ and $F_{j}\left[\xi_{j}(X)\right]$ are index functions:

$$
\begin{gathered}
\begin{cases}H_{i}\left[g_{i}(X)\right]=1, & g_{i}(X)<0 \\
H_{i}\left[g_{i}(X)\right]=0, & g_{i}(X) \geq 0\end{cases} \\
\begin{cases}F_{j}\left[\xi_{j}(X)\right]=1, & \xi_{j}(X) \neq 0 \\
F_{j}\left[\xi_{j}(X)\right]=0, & \xi_{j}(X)=0\end{cases}
\end{gathered}
$$

CSA is adopted to solve the optimization problem. Figure 6 shows the flowchart of the proposed optimization design of the bearing. First, the objective function, design variables, and constraints are defined. Second, the adjustable parameters of the CSA are specified. The parameter of the RV reducer and initial parameters of the bearing are given. The position and memory of the crows is initialized. Third, a new position is generated, and the feasibility of the solution is checked through constraints. The process is repeated until the maximum number of iterations is reached.

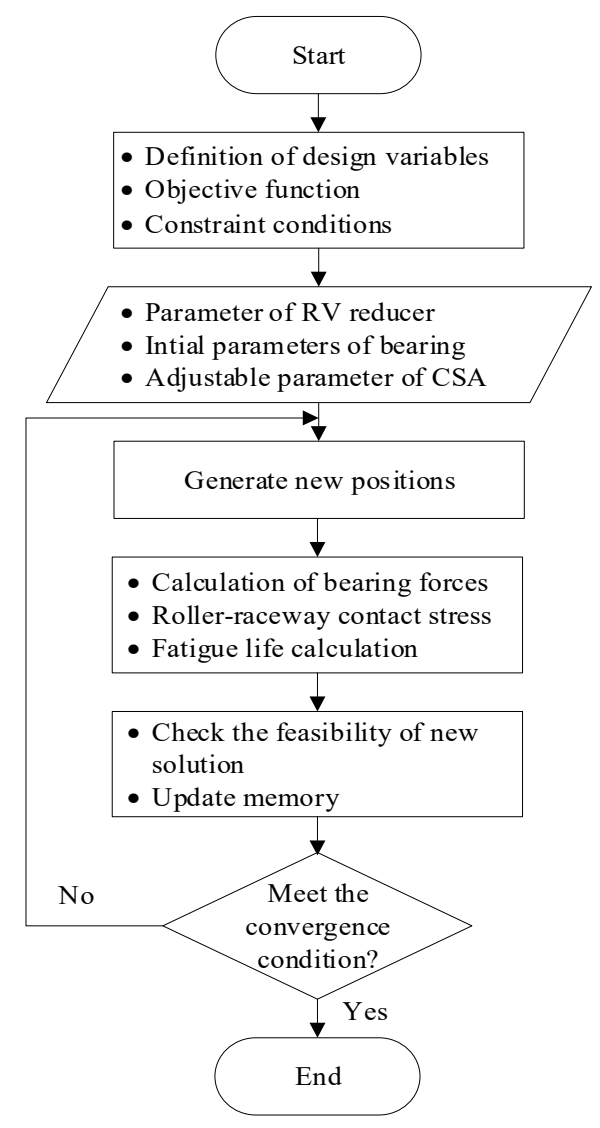

Figure 6. Flowchart of the proposed optimization framework. 


\section{Optimization Example}

The proposed optimization method is applied to the RV 20E and RV 110E-type reducers. The macro geometry and crowned roller profile of crankshaft bearings are optimized. The features of the reducers are listed in Table 1. The grease used is MolywhiteRE00. The output speed of the reducer is $10 \mathrm{rev} / \mathrm{min}$. The optimization is implemented with MATLAB 2017a on a Windows 10 Intel(R) Core(TM) i7-7700 CPU @3.6GHz with 8 GB RAM.

Table 1. RV reducer design parameters.

\begin{tabular}{cccc}
\hline Parameters & & 20E & 110E \\
\hline Number of teeth & $Z_{\mathrm{g}}$ & 39 & 39 \\
Eccentric distance of crankshaft $(\mathrm{mm})$ & $e$ & 0.9 & 1.5 \\
Radius of pin tooth distribution circle $(\mathrm{mm})$ & $R_{z}$ & 52 & 82.5 \\
Radius of pin tooth $(\mathrm{mm})$ & $r_{z}$ & 2 & 3.5 \\
Width of cycloidal gear $(\mathrm{mm})$ & $B$ & 8 & 10 \\
Planet gear module $(\mathrm{mm})$ & $m$ & 1 & 1.25 \\
Diameter of crankshaft bearing $(\mathrm{mm})$ & $D_{L}$ & 12 & 20 \\
diameter of center hole $(\mathrm{mm})$ & $D_{h}$ & 24 & 43 \\
Torque (N.m) & $T_{v}$ & 167 & 1078 \\
\hline
\end{tabular}

\subsection{Optimization Design of Crankshaft Bearing of RV-20E}

The convergence history of the fatigue life of crankshaft bearing of RV-20E is shown in Figure 7. After approximately $4 \mathrm{~h}$ of running time, optimization results satisfying all design constraints are obtained without any difficulty in convergence. The fatigue life increases to 11,896.1 million revolutions after 58 cycles. After this, there are small increases in the fatigue life, and it increases to 13,774.3 million revolutions after 216 cycles.

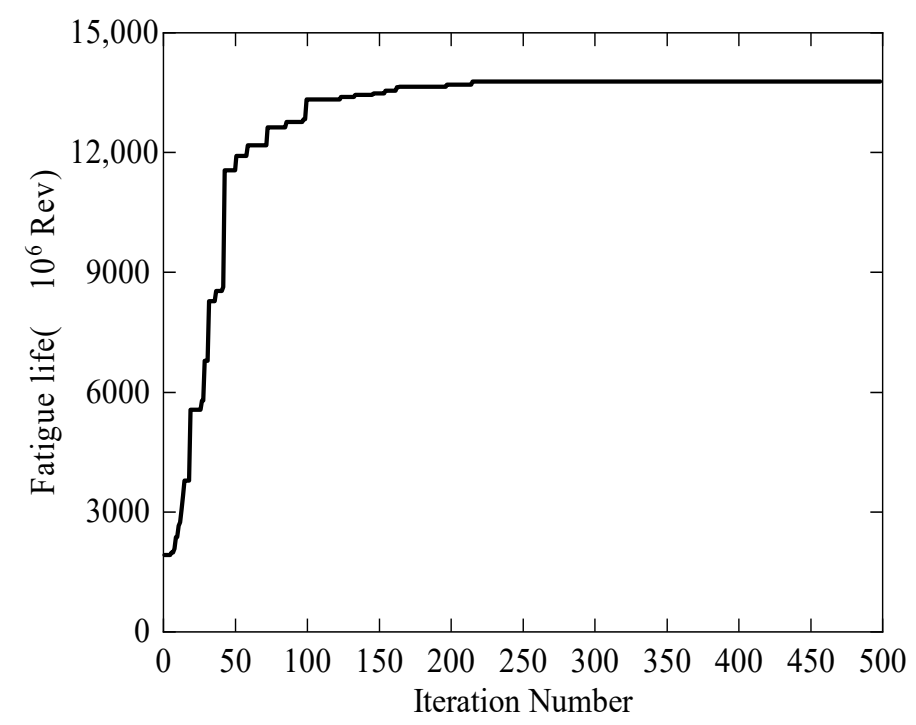

Figure 7. Convergence characteristic of fatigue life of crankshaft bearing of RV-20E.

Table 2 shows the comparison of the parameters before and after optimization. Before optimization, the profile of the roller was flat. Therefore, the values of $k_{1}, k_{2}$, and $Z_{m}$ are set to 0 . In practical situations, the optimization results must be rounded. The rounded parameters and life are also listed in the table. By substituting the optimization variables into the above constraints, it can be known that all optimization variables can satisfy the constraints. Before optimization, the fatigue life of the crankshaft bearing was 4475.4 million revolutions. After optimization, the bearing life is increased to $13,254.2$ million revolutions. The fatigue life after optimization is increased by $196 \%$ compared with 
the life before optimization. After optimization, the value of the clearance is negative. This is because a proper negative clearance increases the bearing life.

Table 2. Comparison of the design variables and fatigue life of RV-20E.

\begin{tabular}{cccc}
\hline Parameters & Before Optimization & After Optimization & Rounded Values \\
\hline$r_{o}(\mathrm{~mm})$ & 27.5 & 30 & 30 \\
$D_{w e}(\mathrm{~mm})$ & 3 & 5.2196 & 5.2 \\
$D_{m}(\mathrm{~mm})$ & 23.5 & 22.7802 & 22.8 \\
$z$ & 23 & 13 & 13 \\
$L_{w e}(\mathrm{~mm})$ & 8 & 8 & 8 \\
$P_{d}(\mu \mathrm{m})$ & 0 & -2.4238 & -2 \\
$K_{1}$ & 0 & 0.9627 & 0.96 \\
$K_{2}$ & 0 & 0.7271 & 0.7 \\
$Z_{m}(\mu \mathrm{m})$ & 0 & 0.0096 & 10 \\
$L_{10 r}\left(10^{6} \mathrm{Rev}\right)$ & 4475.4 & 13774.3 & 13254.2 \\
\hline
\end{tabular}

The structure of the crankshaft bearing of RV-20E before and after optimization is shown in Figure 8 . The space of the cycloid gear is better used after optimization. The structural parameters of the cycloidal gear have not changed during the design optimization. The diameter of outer raceway is increased, while the diameter of the inner raceway is decreased. The roller diameter is increased, but the number of rollers is reduced. This makes the internal structure of the crankshaft bearing more reasonable. In addition, the radius of the crankshaft bearing distribution circle is increased. This is because the load of the crankshaft bearing from the cycloidal gear decreases as the radius of the bearing distribution circle increases.

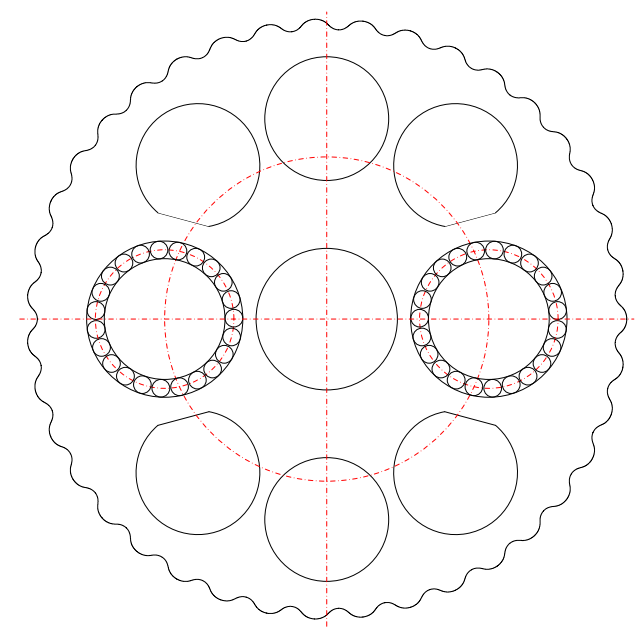

(a)

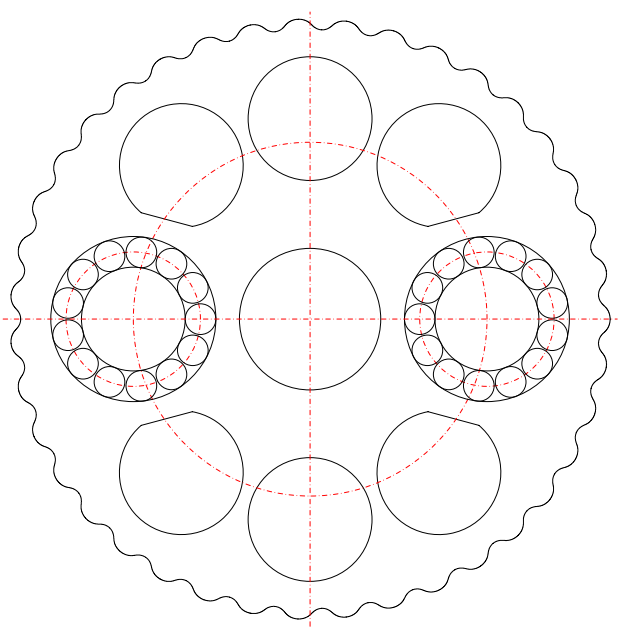

(b)

Figure 8. Diagram of RV-20E crankshaft bearing: (a) Structure of the bearing before optimization;

(b) Structure of the bearing after optimization.

When the minimum thickness of cycloidal gear is too small, the structure strength of the cycloidal gear may be weakened. However, the constraint on the thickness of the cycloidal gear is considered in Section 3.3.8. Therefore, the thickness of the cycloidal gear after optimization will not be too thin. When the inner raceway diameter is too small, the contact stress between the inner raceway and bearings may exceed the strain limit. The constraints on contact strength have been proposed in Section 3.3.6, too. Therefore, the strength of the cycloidal gear and crankshaft bearing is not reduced after optimization. 
The optimization roller profile of crankshaft bearing of RV 20E is shown in Figure 9. The roller profile is partially crowned. The crown drop at roller end is $10 \mu \mathrm{m}$. The ratio of crowning length to effective contact length is 0.7 . The flat region increases the bearing capacity of the roller-raceway. The crown drop eliminates edge stress concentration.

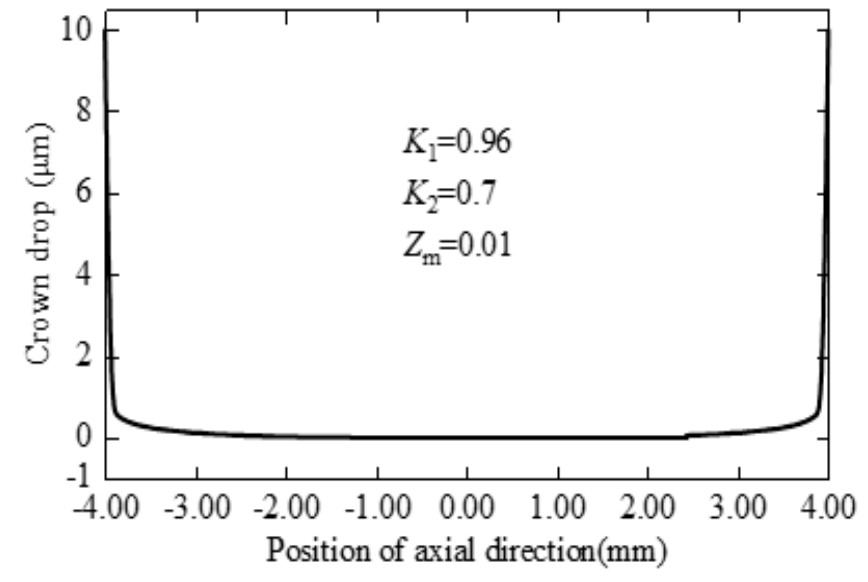

Figure 9. Crown drops of crankshaft bearing rollers of RV-20E.

The contact stress on the roller that bears the maximum load is shown in Figure 10. The contact stress on the contact region was calculated using the non-Hertzian contact method. Before optimization, the contact stress in the middle of the roller was approximately $1400 \mathrm{MPa}$. An extremely large edge stress of $2190 \mathrm{MPa}$ occurred at the end of roller. After optimization, the roller profile suitable for the work condition is obtained. The stress concentration at roller end is eliminated. The maximum contact stress of the roller is only $1245 \mathrm{MPa}$. As the roller diameter is larger, the contact stress between the raceway and roller decreases overall, and the stress in the middle of the roller decreases to $1150 \mathrm{MPa}$.

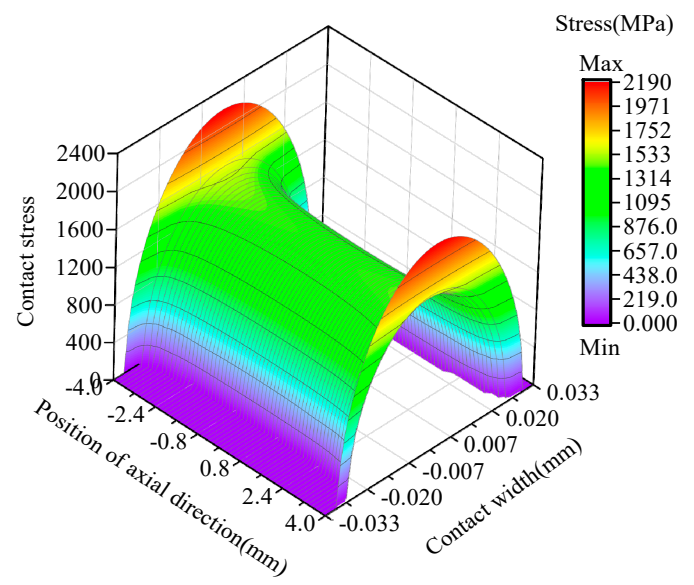

(a)

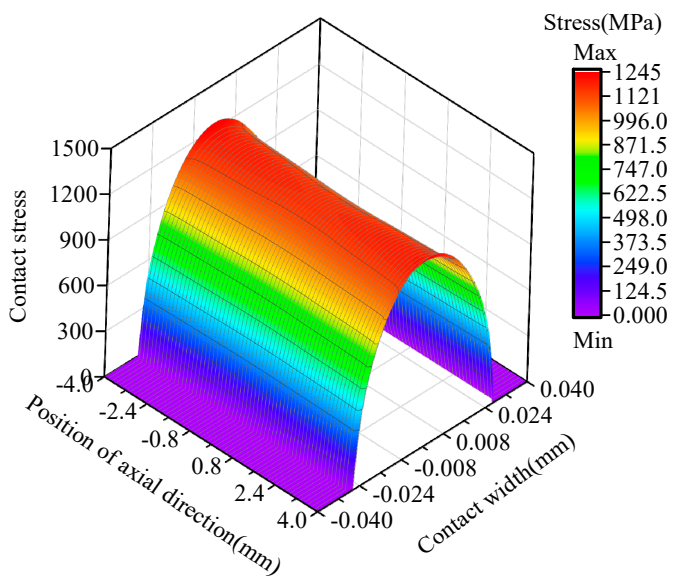

(b)

Figure 10. Contact stress between raceway and roller of crankshaft bearings of RV-20E: (a) Contact stress before optimization; (b) Contact stress after optimization.

\subsection{Optimization Design of Crankshaft Bearing of RV-110E}

The convergence history of the bearing fatigue life of RV-110E is shown in Figure 11. After approximately $4 \mathrm{~h}$ of running time, optimization results satisfying all the design constraints are obtained. The fatigue life increases to 4840.1 million revolutions after 76 cycles. After this, there are small increases in the fatigue life, which increases to 5064.8 million revolutions after 196 cycles. 


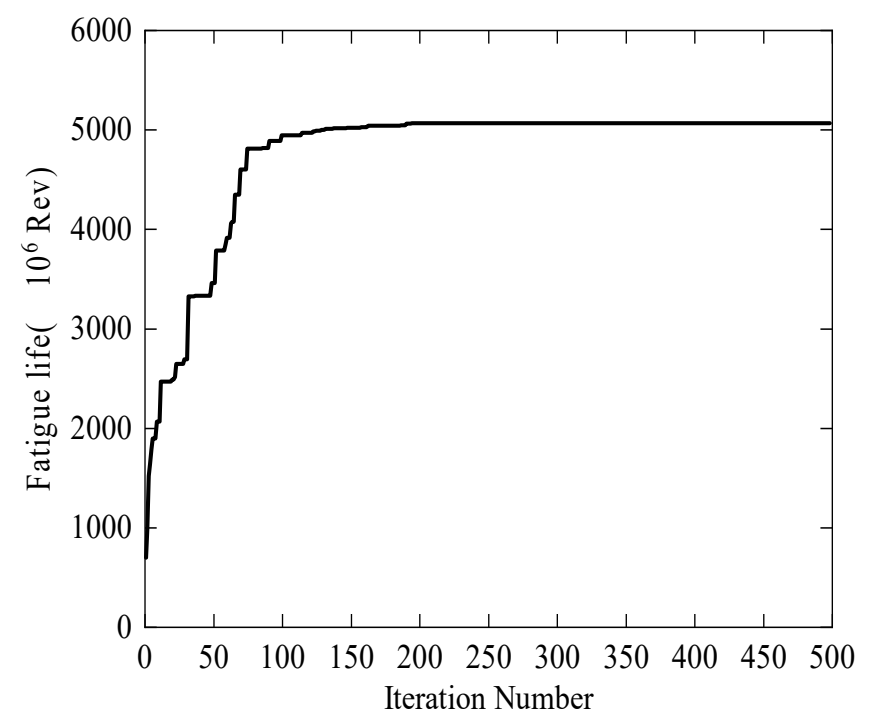

Figure 11. Convergence characteristic of fatigue life of crankshaft bearing of RV-110E.

A comparison of the parameters of RV-110E before and after optimization is presented in Table 3. By substituting the optimization variables into the above constraints, it can be known that all optimization variables can satisfy the constraints. Before optimization, the fatigue life of the crankshaft bearing was 1912.2 million revolutions. After optimization, the bearing life is increased to 5125.3 million revolutions. The fatigue life after optimization is increased by $168 \%$ compared with that before optimization.

Table 3. Comparison of the design variables and fatigue life of RV-110E.

\begin{tabular}{cccc}
\hline Parameters & Before Optimization & After Optimization & Rounded Values \\
\hline$r_{o}(\mathrm{~mm})$ & 46.875 & 48.75 & 48.75 \\
$D_{w e}(\mathrm{~mm})$ & 6 & 9.3109 & 9.3 \\
$D_{m}(\mathrm{~mm})$ & 36 & 37.189 & 37.2 \\
$z$ & 18 & 12 & 12 \\
$L_{w e}(\mathrm{~mm})$ & 10 & 10 & 10 \\
$P_{d}(\mu \mathrm{m})$ & 0 & -6.4545 & -6 \\
$K_{1}$ & 0 & 1.118 & 1.12 \\
$K_{2}$ & 0 & 0.6317 & 0.63 \\
$Z_{m}(\mu \mathrm{m})$ & 0 & 12.1601 & 12 \\
$L_{10 r}\left(10^{6} \mathrm{Rev}\right)$ & 1912.2 & 5183.26 & 5125.3 \\
\hline
\end{tabular}

Figure 12 shows the structure of the crankshaft bearing of RV-110E before and after optimization. For RV-110E, the change in the structure of the crankshaft bearings is similar to that of RV-20E. The outer raceway diameter and roller diameter are also increased. The inner raceway diameter is decreased, and the number of rollers is reduced. The radius of the crankshaft bearing distribution circle is also increased. Although these dimensions have been changed, due to the constraints, the amount of change is within a limited range. Therefore, the change will not weaken the cycloidal gear and crankshaft. 


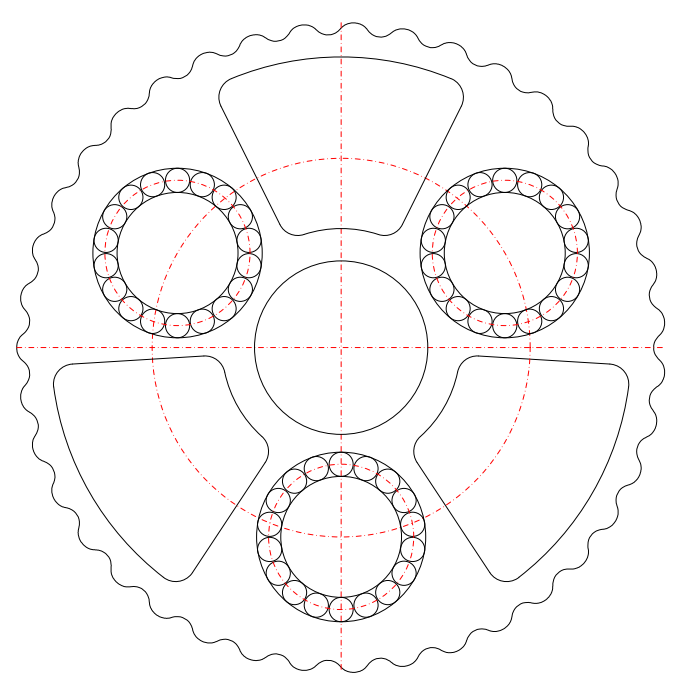

(a)

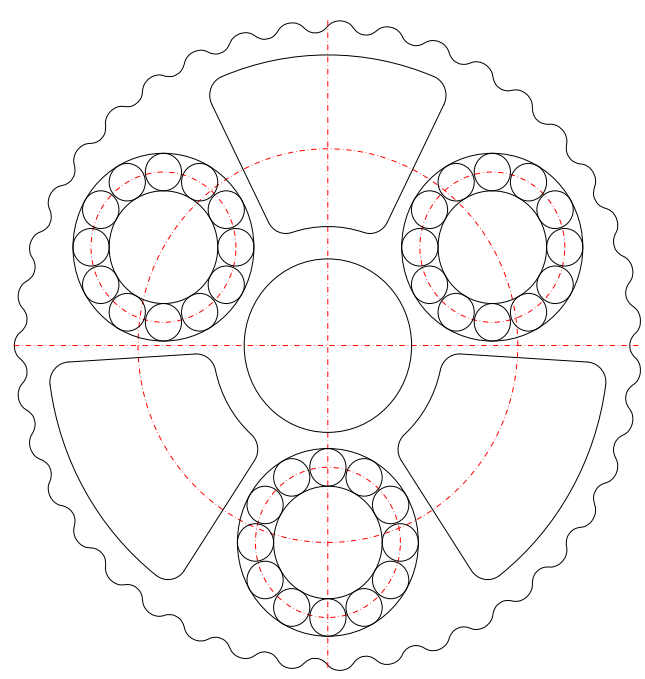

(b)

Figure 12. Diagram of crankshaft bearing of RV-110E: (a) Structure of the crankshaft bearing before optimization; (b) Structure of the crankshaft bearing after optimization.

Figure 13 shows the crown drops of crankshaft bearing rollers of RV-110E. The crown drop at the end of the roller is $12 \mu \mathrm{m}$. The ratio of the crowning length to the effective contact length is 0.63 . The roller diameter is increased after optimization, which helps to reduce the contact stress between the raceway and the roller.

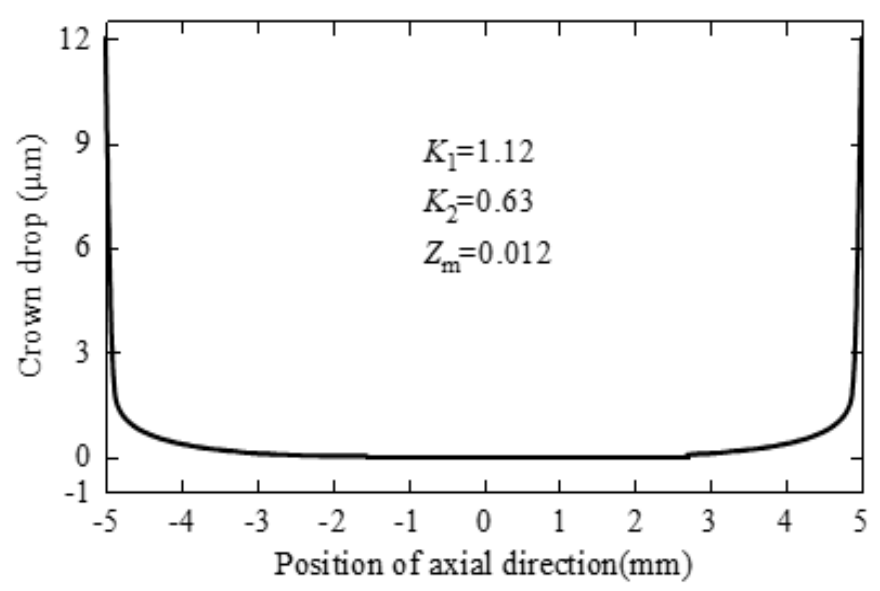

Figure 13. Crown drops of crankshaft bearing rollers of RV-110E.

The contact stress on the roller that bears the maximum load is shown in Figure 14. Before optimization, the flat profile of the roller resulted in edge stress concentrations at the roller ends. The stress in the middle of the roller was approximately $1500 \mathrm{MPa}$. The maximum stress was $2660 \mathrm{MPa}$ at the end of the roller. After optimization, the edge stress concentration is effectively eliminated. The maximum stress on the roller is reduced to $1380 \mathrm{MPa}$. The stress in the middle of the roller is reduced to $1300 \mathrm{MPa}$. The distribution of the contact stress over the length of the roller is much more uniform. This is beneficial for increasing the bearing life. 


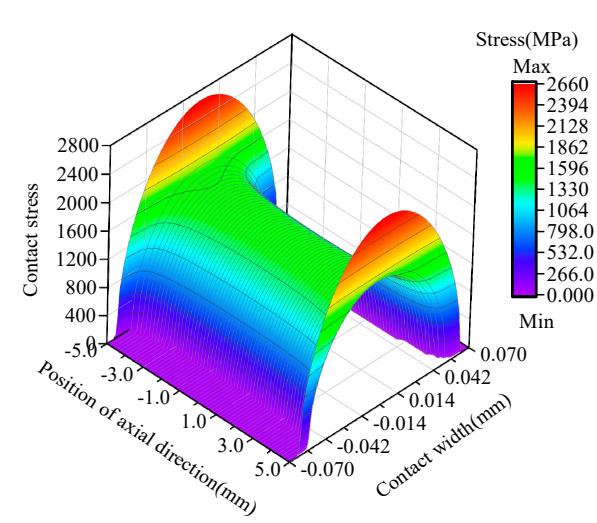

(a)

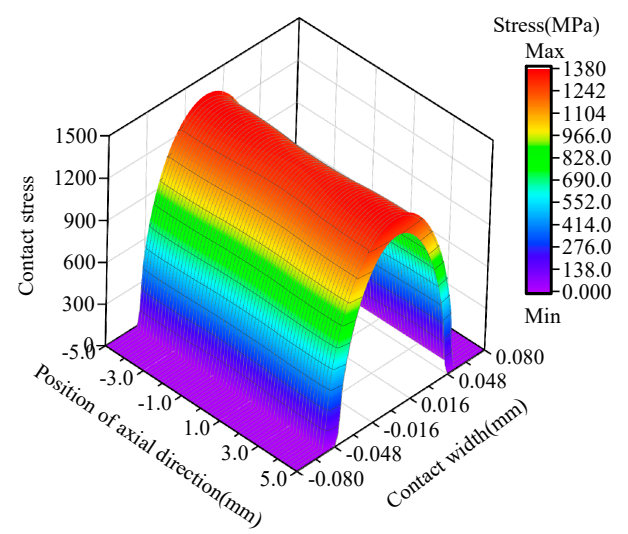

(b)

Figure 14. Contact stress between raceway and roller of crankshaft bearings of RV-110E: (a) Contact stress before optimization; (b) Contact stress after optimization.

\section{Conclusions}

This study proposes a novel optimization method for RV reducer crankshaft bearings considering the bearing geometry and crowned roller profile. The working load of the bearing and the structure of the reducer are considered. Constraints derived from the geometry, lubrication, strength of crankshaft bearings, and structure of the RV reducer are established. The fatigue life of the bearing is optimized by the proposed optimization method. The research summary of conclusions is as follows:

(1) A comprehensive optimization design model of an RV reducer crankshaft bearing is constructed. Based on the CSA algorithm, a nonlinear constraint optimization program is developed to solve the optimization problem. The convergence process shows that the optimization program has high efficiency and ability to solve the optimization problem of RV reducer crankshaft bearings.

(2) The roller profile and macro-geometric parameters of the bearing are both considered in this study. Through the optimization design, the optimum crowned roller profile suitable for the working load of the bearing is obtained, and the stress concentration between the roller and the raceway is eliminated. Compared with the situation before optimization, the limited geometric space of the cycloidal gear is used more effectively.

(3) Taking the RV-20E and RV-110E reducer crankshaft bearings as examples, the two bearings are optimized by the proposed method. After optimization, all the optimization variables satisfy the constraint conditions. The RV-20E bearing life is increased by 196\%, whereas that of the RV110 is increased by $168 \%$.

The optimization design method proposed in this study has an important guiding significance for improving the service life of RV reducers. It can thus provide a theoretical basis for the design of RV reducer crankshaft bearings. The optimization method developed in this study can also be used in the design of other nonstandard roller bearings

Author Contributions: The work described in this article is the collaborative development of all authors. C.L. and J.H. contributed to the idea of the optimization model and participated in the writing of the paper. B.C. contributed to the validation of the method and funding acquisition. All authors have read and agreed to the published version of the manuscript.

Funding: This research was supported by the National Key Research \& Development Program of China (Grant No. 2017YFB1300700); National Natural Science Foundation of China (Grant No. 51775059).

Conflicts of Interest: The authors declare no conflict of interest. 


\section{References}

1. Ren, Z.-Y.; Mao, S.-M.; Guo, W.-C.; Guo, Z. Tooth modification and dynamic performance of the cycloidal drive. Mech. Syst. Signal Process. 2017, 85, 857-866. [CrossRef]

2. Li, T.; An, X.; Deng, X.; Li, J.; Li, Y. A New Tooth Profile Modification Method of Cycloidal Gears in Precision Reducers for Robots. Appl. Sci. 2020, 10, 1266. [CrossRef]

3. Qian, H.-M.; Li, Y.; Huang, H.Z. Time-variant reliability analysis for industrial robot RV reducer under multiple failure modes using Kriging model. Reliab. Eng. Syst. Saf. 2020, 199, 106936. [CrossRef]

4. Xu, L.X.; Chen, B.K.; Li, C.Y. Dynamic modelling and contact analysis of bearing-cycloid-pinwheel transmission mechanisms used in joint rotate vector reducers. Mech. Mach. Theory 2019, 137, 432-458. [CrossRef]

5. Zhang, Z.; Wang, J.; Zhou, G.; Pei, X. Analysis of mixed lubrication of RV reducer turning arm roller bearing. Ind. Lubr. Tribol. 2018, 70, 161-171. [CrossRef]

6. Kim, S.-W.; Kang, K.; Yoon, K.; Choi, D.-H. Design optimization of an angular contact ball bearing for the main shaft of a grinder. Mech. Mach. Theory 2016, 104, 287-302. [CrossRef]

7. Li, X.; Li, C.; Wang, Y.; Chen, B.; Lim, T.C. Analysis of a Cycloid Speed Reducer Considering Tooth Profile Modification and Clearance-Fit Output Mechanism. J. Mech. Des. 2017, 139, 033303. [CrossRef]

8. Han, L.; Guo, F. Global sensitivity analysis of transmission accuracy for RV-type cycloid-pin drive. J. Mech. Sci. Technol. 2016, 30, 1225-1231. [CrossRef]

9. Xu, H.; Shi, Z.; Yu, B.; Wang, H. Dynamic measurement of the lost motion of precision reducers in robots and the determination of optimal measurement speed. J. Adv. Mech. Des. Syst. Manuf. 2019, 13. [CrossRef]

10. Hsieh, C.-F. Traditional versus improved designs for cycloidal speed reducers with a small tooth difference: The effect on dynamics. Mech. Mach. Theory 2015, 86, 15-35. [CrossRef]

11. Jin, S.-S.; Tong, X.-T.; Wang, Y.-L. Influencing Factors on Rotate Vector Reducer Dynamic Transmission Error. Int. J. Autom. Technol. 2019, 13, 545-556. [CrossRef]

12. Wang, H.; Shi, Z.-Y.; Yu, B.; Xu, H. Transmission Performance Analysis of RV Reducers Influenced by Profile Modification and Load. Appl. Sci. 2019, 9, 4099. [CrossRef]

13. Li, T.; Tian, M.; Xu, H.; Deng, X.; An, X.; Su, J. Meshing contact analysis of cycloidal-pin gear in RV reducer considering the influence of manufacturing error. J. Braz. Soc. Mech. Sci. Eng. 2020, 42, 1-14. [CrossRef]

14. Chen, C.; Yang, Y. Structural Characteristics of Rotate Vector Reducer Free Vibration. Shock Vib. 2017, 2017, 1-14. [CrossRef]

15. Wei, B.; Wang, J.; Zhou, G.; Yang, R.; Zhou, H.; He, T. Mixed lubrication analysis of modified cycloidal gear used in the RV reducer. Proc. Inst. Mech. Eng. Part J J. Eng. Tribol. 2015, 230, 121-134. [CrossRef]

16. Wang, J.; Luo, S.; Su, D. Multi-objective optimal design of cycloid speed reducer based on genetic algorithm. Mech. Mach. Theory 2016, 102, 135-148. [CrossRef]

17. Chu, X.; Xu, H.; Wu, X.; Tao, J.; Shao, G. The method of selective assembly for the RV reducer based on genetic algorithm. Proc. Inst. Mech. Eng. Part C J. Mech. Eng. Sci. 2018, 232, 921-929. [CrossRef]

18. Wang, Y.; Qian, Q.; Chen, G.; Jin, S.; Chen, Y. Multi-objective optimization design of cycloid pin gear planetary reducer. Adv. Mech. Eng. 2017, 9, 9. [CrossRef]

19. Harris, T.A.; Kotzalas, M.N. Advanced Concepts of Bearing Technology: Rolling Bearing Analysis; CRC Press: Boca Raton, FL, USA, 2006.

20. Mevel, B. Numerical Methods in Bearing Roller Tilt Analysis. Tribol. Trans. 2016, 59, 1081-1088. [CrossRef]

21. Fujiwara, H.; Kobayashi, T.; Kawase, T.; Yamauchi, K. Optimized Logarithmic Roller Crowning Design of Cylindrical Roller Bearings and Its Experimental Demonstration. Tribol. Trans. 2010, 53, 909-916. [CrossRef]

22. Fujiwara, H.; Kawase, T. Logarithmic profile of rollers in roller bearing and optimization of the profile. Trans. Jpn. Soc. Mech. Eng. Part C 2006, 18, 3022-3029. [CrossRef]

23. Waghole, V.; Tiwari, R. Optimization of needle roller bearing design using novel hybrid methods. Mech. Mach. Theory 2014, 72, 71-85. [CrossRef]

24. Harris, T.A.; Kotzalas, M.N. Essential Concepts of Bearing Technology; CRC Press: Boca Raton, FL, USA, 2006.

25. Dowson, D.; Higginson, G.R.; Nielsen, K.W. Elasto-Hydrodynamic Lubrication (International Series in Material, Science and Technology, Vol. 23). J. Lubr. Technol. 1978, 100, 447. [CrossRef]

26. Rajeswara Rao, B.; Tiwari, R. Optimum design of rolling element bearings using genetic algorithms. Mech. Mach. Theory 2007, 42, 233-250. [CrossRef] 
27. Askarzadeh, A. A novel metaheuristic method for solving constrained engineering optimization problems: Crow search algorithm. Comput. Struct. 2016, 169, 1-12. [CrossRef]

28. Meddeb, A.; Amor, N.; Abbes, M.; Chebbi, S. A Novel Approach Based on Crow Search Algorithm for Solving Reactive Power Dispatch Problem. Energies 2018, 11, 3321. [CrossRef] 